\title{
Carotid sinus syndrome as the presenting symptom of cystadenolymphoma
}

\author{
Nelson Noroozi ${ }^{1 \dagger}$, Ali Modabber ${ }^{1 * \dagger}$, Frank Hölzle ${ }^{1}$, Till Braunschweig ${ }^{2}$, Dieter Riediger ${ }^{1}$, Marcus Gerressen ${ }^{3}$ and \\ Alireza Ghassemi ${ }^{1}$
}

\begin{abstract}
Carotid sinus syndrome is a serious manifestation of head and neck malignancy. The purpose of this study was to clarify the presence of carotid sinus syndrome in a patient with cystadenolymphoma. To our knowledge carotid sinus syndrome secondary to cystadenolymphoma has not been reported to date. A 45-year-old woman with one-week-old swelling in the left mandibular angle having disturbing symptoms of vertigo, consciousness and sinus arrest. Holter monitoring revealed several episodes of sinus arrest. Ultrasonography showed a well-defined space-occupying lesion of about $31 \mathrm{~mm}$ in length and $17 \mathrm{~mm}$ in width located in the deep lobe of the left parotid gland. Computerized tomography (CT) showed a large mass extending into the carotid space and protruding into the parapharyngeal space. Parotidectomy was performed. Surgical removal of the tumor resulted in complete amelioration of symptoms and disappearance of electrocardiogram abnormalities. Here we report on a clinical case of carotid sinus syndrome associated with cystadenolymphoma. To our knowledge carotid sinus syndrome secondary to cystadenolymphoma has not been reported to date, and is made more remarkable as a possible differential diagnosis after clarification of all possible causes. Early diagnosis and immediate management can minimize complications.
\end{abstract}

Keywords: Cystadenolymphoma, Warthin's tumor, Parotid gland tumors, Syncope, Carotid sinus syndrome

\section{Background}

Carotid sinus syndrome is a rare but serious manifestation of head and neck malignancy [1]. Although a number of different types of the syndrome have been proposed by Weiss and Baker [2], it is not always easy to fit a patient into these categories. However, to our knowledge, this is the first report of cystadenolymphoma presenting as recurrent syncopal episodes, and the surgical removal of the tumor resulted in complete amelioration of symptoms and disappearance of electrocardiogram abnormalities.

\section{Case report}

A 45-year-old woman with one-week-old swelling in the left mandibular angle was admitted to our oral and maxillofacial surgery department with the complaints of recurrent episodes of vertigo and consciousness. The

\footnotetext{
* Correspondence: amodabber@ukaachen.de

${ }^{\dagger}$ Equal contributors

${ }^{1}$ Department of Oral, Maxillofacial and Plastic Facial Surgery, University Hospital RWTH-Aachen, Pauwelsstraße 30, Aachen 52074, Germany Full list of author information is available at the end of the article
}

vertigos gradually increased in frequency and intensity since they started one month prior her admission. Physical examination revealed a discrete raised, painless mass occupying the left parotid area witch adhered to underlying soft tissue, extending approximately $2 \mathrm{~cm}$ in diameter in the sub- and retromandibular regions. There were no restrictions on the cranial nerves supplying this area. No odontogenic cause or any other inflammatory factors could be responsible for the parotid gland swelling. There was no palpable lymphadenopathy in the left neck. Blood pressure was $115 / 62 \mathrm{~mm} \mathrm{Hg}$ and the heart rate was 63 beats per minute. Routine laboratory investigations were normal. 24-hour Holter monitoring revealed several episodes of sinus arrest. Ultrasonography showed a well-defined space-occupying lesion of about $31 \mathrm{~mm}$ in length and $17 \mathrm{~mm}$ in width, which was hypo echoic and located in the deep lobe of the left parotid gland. The rest of the gland showed a homogeneous parenchyma.

Computerized tomography (CT) showed a large mass extending into the carotid space and protruding into the parapharyngeal space (Figure 1). 


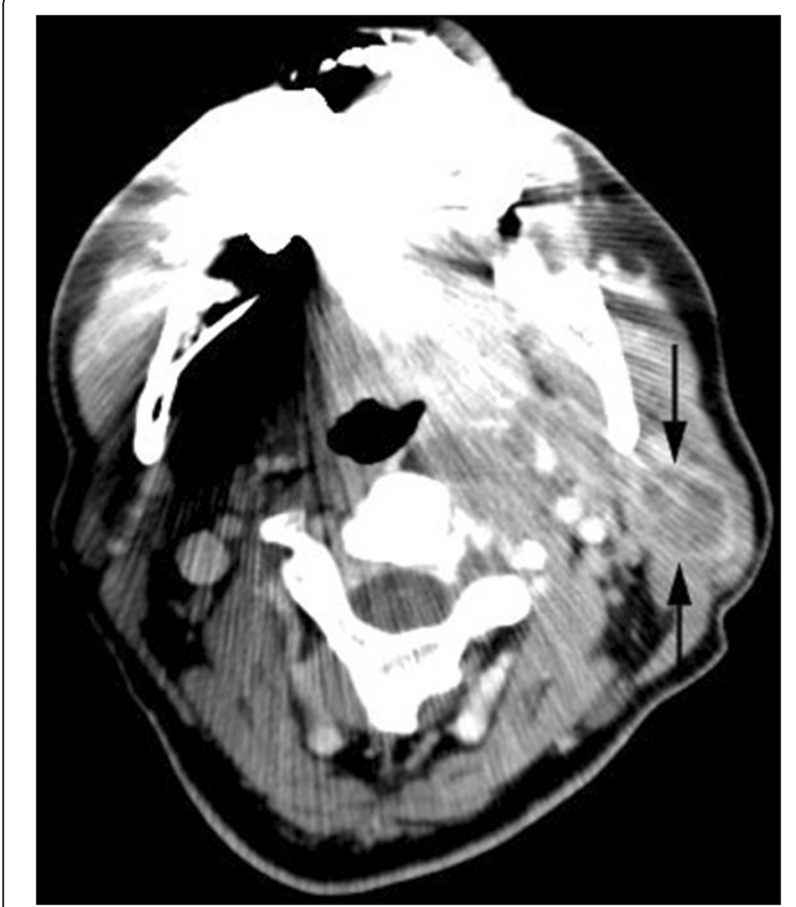

Figure 1 Computerized tomography (CT) at the level of the submandibular area demonstrating the mass of the left parotid gland extending into the carotid space.

A left parotidectomy was performed. The resected gland was a hard mass, which had spread over the bifurcation of the left carotid artery without invading the vessel wall itself. The tumor was oval-shaped, encapsulated, and partially nodular without any regional lymph gland involvement. Upon opening the mass viscous, whitecolored fluid was released (Figure 2A/B).

The pathology report showed a lymphoid tissue with multifocal double-row hypereosinophilic epithelium with retention of thickened secretions in the lumen as well as squamous cell metaplasia consistent with typical parotid gland cystadenolymphoma (Figure 3A/B).

The patient started ambulating from the second postoperative day without any symptoms of vertigo and consciousness. 24-hour Holter monitoring was repeated on three occasions at weekly intervals and revealed regular sinus rhythm at a rate of 80 to 90 per minute. 6 months postoperatively, the patient was asymptomatic.

\section{Discussion and conclusion}

The carotid sinus, located just superior to the bifurcation of the carotid artery controls the heart rate and blood pressure via receptors located within the arterial adventitia. The afferent limb of the carotid sinus reflex begins with these receptors [3]. Myelinated nerve fibers emerge from these menisci as spiral fibers and from the sinus nerve of Hering, a branch of the glossopharyngeal nerve.

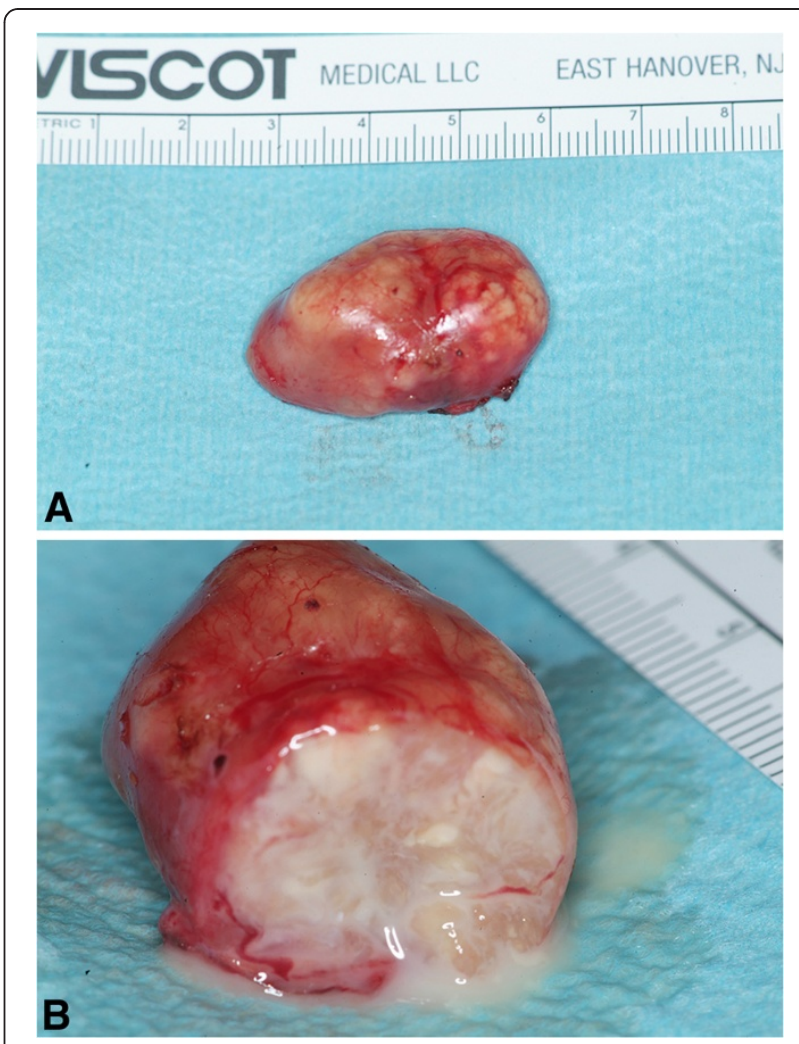

Figure 2 A/B: 2A:The tumor was oval-shaped, encapsulated, and partially nodular without any regional lymph gland involvement. 2B: Upon opening the mass viscous, white-colored fluid was released.

Other fibers may follow the hypoglossal nerve, vagus nerve or cervical sympathetic nerves to the medulla. The efferent fibers descend in the vagus and cervical sympathetic nerves to the cardioinhibitory and vasomotor centers $[4,5]$. The carotid sinus syndrome consists of a cardiovascular symptom complex resulting from excitation of a hyperactive carotid sinus reflex. Weiss and Baker [2] classified three types of responses leading to carotid sinus stimulation. Cardioinhibitory response, which is expressed as bradycardia and asystole, vasodepressor response, characterized by profound hypotension without bradycardia, and cerebral response, which is an interference with the circulation of the ipsilateral cerebral hemisphere circulation [6]. The pathophysiology of carotid sinus syndrome secondary to head and neck malignancy is not well understood. Local pathologic conditions adjacent to the carotid sinus such as enlarged lymph nodes, operation scars, and mechanical pressure by a mass on carotid sinus or by actual invasion of the carotid sinus, sinus nerve or glossopharyngeal nerve by tumor have been postulated to produce carotid sinus syndrome $[1,4,7,8]$.

The tumor may cause either a spontaneous abnormal afferent discharge in the damaged nerve itself or may lead to ephaptic conduction, either between glossopharyngeal 


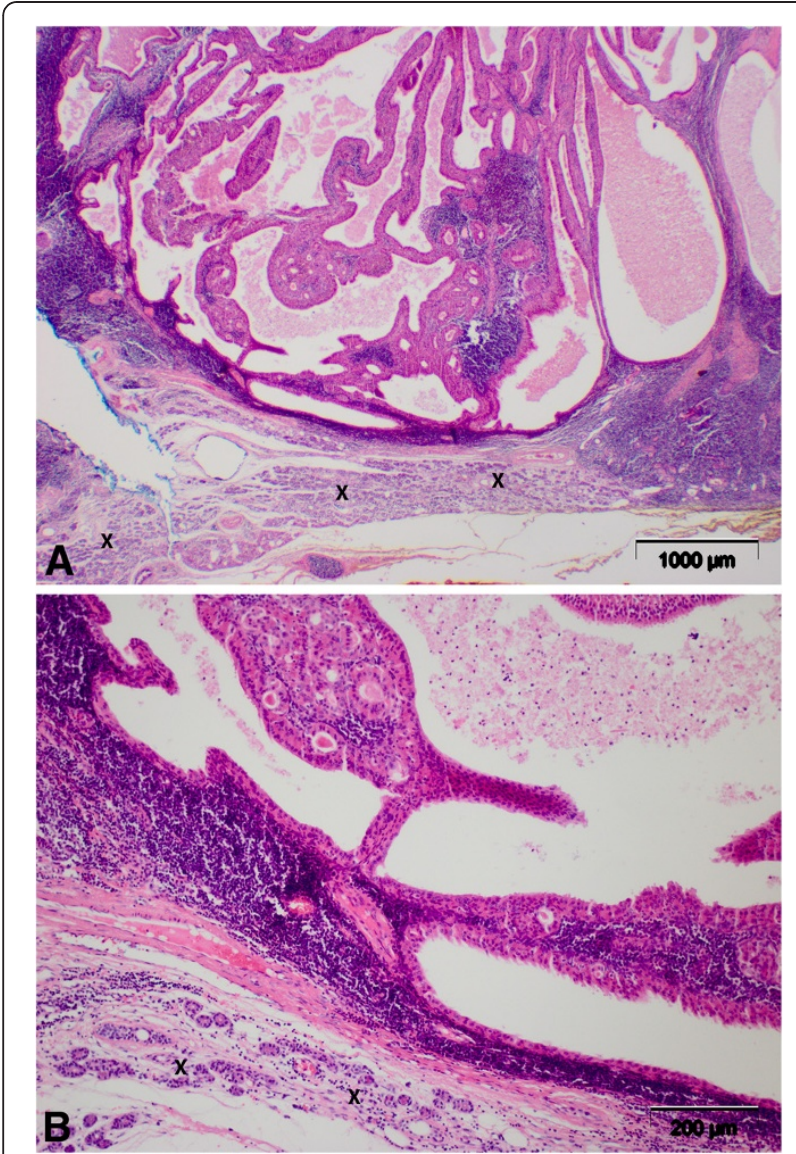

Figure 3 A/B: Hematoxylin-eosin (H\&E) parotid gland (x), adjacent lymph nodes with glandular-epithelial formations. (3A: original magnification $\times 25$; $3 \mathbf{B}$ : original magnification $\times 100$ ).

efferent motor fibers and afferent sinus sensory fibers or between the glossopharyngeal nerve and other nearby nerves, inducing an abnormally strong carotid sinus reflex. It also been postulated that compression of the nerve outside of the carotid sinus reflex arc, such as the glossopharyngeal nerve, can cause carotid sinus syndrome [9-13].

It is more likely that head and neck tumors cause syncope by involvement of the glossopharyngeal or vagus nerve in those patients in whom carotid sinus massage does not induce syncope.

The majority of reports of carotid sinus syndrome associated with head and neck malignancy relate to extensive nodal involvement in the neck [14].

The immediate treatment of carotid sinus syndrome includes anticholinergic medications and cardiac pacing. Surgery is reserved for those who fail medical therapy [15]. Radiation therapy is occasionally beneficial [16].

In our presented case the disturbing symptoms of vertigo, consciousness and sinus arrest, all disappeared following resection of the parotid tumor. We postulate that the tumor produced sustained compression on the carotid sinus resulting in carotid sinus syndrome. The patient was followed postoperatively for 6 months without any clinical symptoms. In summary, this is the first report of carotid sinus syndrome exacerbated by a benign parotid tumor and is made more remarkable here as a possible differential diagnosis after clarification of all possible causes. Early diagnosis and immediate management can minimize complications. Resection of the tumor resulted in amelioration of symptoms and disappearance of electrocardiography abnormalities.

\section{Consent statement}

Written informed consent was obtained from the patient for publication of this case report and accompanying images. A copy of the written consent is available for review by the Editor-in-Chief of this journal.

\section{Competing interests}

The authors declare that they have no competing interests.

\section{Authors' contributions}

$N N, A M, F H, T B, D R, M G$ and $A G$ conceived of the study and participated in its design and coordination. $\mathrm{NN}$ and $\mathrm{AM}$ drafted the manuscript and contributed equally to this work. NN, AM, MG and AG were involved in revising the manuscript. All authors read and approved the final manuscript.

\section{Author details}

'Department of Oral, Maxillofacial and Plastic Facial Surgery, University Hospital RWTH-Aachen, Pauwelsstraße 30, Aachen 52074, Germany. ${ }^{2}$ Institute of Pathology, University Hospital RWTH-Aachen, Aachen, Germany.

${ }^{3}$ Department of Oral, Maxillofacial and Plastic Facial Surgery, Heinrich-Braun Hospital Zwickau, Zwickau, Germany.

Received: 15 October 2012 Accepted: 12 November 2012 Published: 14 November 2012

\section{References}

1. Córdoba López A, Torrico Román P, Inmaculada Bueno Alvarez-Arenas M, Monterrubio Villar J, Corcho Sánchez G: Syncope due to parapharyngeal space lesions syncope-syndrome. Rev Esp Cardiol 2001, 54:649-651.

2. Weiss S, Baker JP: The carotid sinus reflex in health and disease: its role in the causation of fainting and convulsions. Medicine 1933, 12:297-354.

3. Lown B, Levine SA: The carotid sinus. Clinical values of its stimulation. Circulation 1961, 23:766-789.

4. Patel AK, Yap VU, Fields J, Thomsen JH: Carotid sinus syncope induced by malignant tumors in the neck. Arch Intern Med 1979, 139:1281-1284.

5. Walter PF, Grawley IS, Dorney ER: Carotid sinus hypersensitivity and syncope. Am J Cardiol 1978, 42:396-403.

6. Cicogna R, Cumis A, Del Cas L, Visioli O: Syncope and tumors in the neck: carotid sinus or glossopharyngeal syndrome? Eur Heart J 1985, 6:979-984.

7. Farr HW: Carotid body tumors: a 40-year study. CA Cancer J Clin 1980, 30:260-265.

8. Sutherland JA, Stobie P, Swarup V, Tierney SP, Lin AC, Burke MC: Hypertensive carotid sinus syndrome Due to neurofibromatosis-1 and manifested by repeated episodes of syncope. Pacing Clin Electrophysiol 2004, 27:1571-1573.

9. Dysman TR, Montgomery EB, Gerstenberger PD: Glossopharyngeal neuralgia with syncope secondary to tumour: treatment and pathophysiology. Am J Med 1981, 71:165-170.

10. Kim SS, Lal R, Ruffy R: Bradycardia and vasodepressor syncope secondary to glossopharyngeal neuralgia from hypopharyngeal tumour. Am J Heart 1985, 109:1101-1105.

11. Lin RH, Teng MM, Wang SJ, Yeh TP, Liao KK, Liu HC: Syncope as the presenting symptom of nasopharyngeal carcinoma. Clin Neurol Neurosurg 1994, 96:152-155.

12. Macdonald DR, Strong E, Nielsen S, Posner JB: Syncope from head and neck cancer. J Neurooncol 1983, 1:257-267. 
13. Tulchinsky M, Krasnow SH: Carotid sinus syndrome associated with an occult primary nasopharyngeal carcinoma. Arch Intern Med 1988, 148:1217-1219.

14. Papay FA, Roberts JK, Wegryn TL, Gordon T, Levine HL: Evaluation of syncope from head and neck cancer. Laryndoscope 1989, 99:382-388.

15. Hong AM, Pressley L, Stevens GN: Carotid sinus syndrome secondary to head and neck malignancy: case report and literature review. Clin Oncol 2000, 12:409-412.

16. Muntz HR, Smith PG: Carotid sinus hypersensitivity: a cause of syncope in patient with tumour of head and neck cancer. Laryngoscope 1983, 93:1290-1293.

doi:10.1186/1746-160X-8-31

Cite this article as: Noroozi et al:: Carotid sinus syndrome as the

presenting symptom of cystadenolymphoma. Head \& Face Medicine 2012 8:31.

\section{Submit your next manuscript to BioMed Central and take full advantage of:}

- Convenient online submission

- Thorough peer review

- No space constraints or color figure charges

- Immediate publication on acceptance

- Inclusion in PubMed, CAS, Scopus and Google Scholar

- Research which is freely available for redistribution 